\title{
THE DEVELOPMENT OF A MEASURE OF PERCEIVED HOMOPHILY IN INTERPERSONAL COMMUNICATION
}

\author{
JAMES C. MCCROSKEY \\ West Virginia University
}

\author{
VIRGINIA P. RICHMOND \\ University of Nebraska
}

\author{
and \\ JOHN A. DALY \\ Purdue University
}

\begin{abstract}
This paper reports the development of a measure of perceived homophily. In both an initial investigation and in four subsequent studies employing samples from diverse populations, four dimensions of response were observed. These dimensions were labeled Attitude, Morality, Appearance, and Background. Additional results indicated that opinion leaders are perceived as more homophilous than non-opinion leaders on the dimensions of Attitude, Morality, and Background. The scales found to measure these dimensions are suggested for consideration by researchers concerned with homophily or interpersonal similarity in human communication.
\end{abstract}

One of the most basic principles of interpersonal communication is that source-receiver similarity (homophily) increases the likelihood of communication attempts and promotes communication effectiveness (Rogers \& Bhowmik, 1970; Rogers \& Shoemaker, 1971). Although this general principle has been supported in numerous studies, recent research indicates that the principle must be modified to account for the fact that certain moderate dissimilarities between generally homophilous communicators appear to enhance effectiveness even to a greater degree (Simons, Berkowitz \& Moyer, 1970; Alpert \& Anderson, 1972; King \& Sereno, 1973). Rogers and Shoemaker (1971) refer to this relationship as "optimal heterophily." The best example of this relationship between communicators is the opinion leader-follower relationship commonly observed in mass communication and diffusion research.

Measurement of communicator homophily has taken a variety of forms. Most field investigators have judged communicator homophily on the basis of observer coding of the characteristics of the individuals studied (for an excellent summary of this research, see Rogers \& Shoemaker, 1971). Some laboratory investigations have also employed this approach. Others have asked subjects to complete various scales concerning themselves so that the investigator can estimate the degree of homophily present (Byrne, 1961). Still others have asked subjects to complete various scales on themselves and on other persons so that the investigator can estimate the subject-perceived homophily present (Alpert \& Anderson, 1973). Each of these approaches has produced meaningful research results which have led to the present theoretical formulations. Each, however, includes an element which can introduce error into the research and reduce the value of the research results. In every case, the investigator, not the subject, is the determiner of the degree of homophily present. Thus, subtle, but important dissimilarities among subjects can be overlooked, or similarities apparent to observers may not be perceived by subjects, causing the resultant theory have reduced validity.

The assumption underlying the current investigation is that people's perceptions of other people determine to a major extent whether there is a communication attempt made, and have a major impact on the results of any communication encounter. The results of the research on source credibility and interpersonal attraction strongly support the validity of this assumption (Berscheid \& Walster, 1969; Littlejohn, 1971; Wheeless, 1973). Consequently, 
it is important that an approach to the measurement of homophily be developed that is based on subjects' perceptions without the imposition of investigator interpretation. The current study was undertaken as an initial step toward that goal.

\section{GENERATION OF RESEARCH INSTRUMENT}

The number of elements of similaritydissimilarity between two people approaches infinity. It was recognized at the outset that a single investigation could not hope to isolate all of the possible similarities-dissimilarities that people can perceive in one another. Thus, it was important to reduce to manageable proportions this initial effort by excluding some known areas of similaritydissimilarity which could be investigated later. The primary areas excluded were the dimensions observed in previous research on source credibility. Though it was recognized that these perceptions of communicators are vitally important to interpersonal communication, currently available instruments for the measurement of source credibility (see, e.g., McCroskey, Jensen \& Valencia, 1973) can be converted easily to measure perceived homophily on the various dimensions. For example a scale used to measure Competence in the McCroskey, Jensen, and Valencia (1973) instrument would appear as follows:

\section{Competent 1234567 Incompetent}

This could be converted to the following form to measure perceived similarity:

Much More Competent 1234 ME 6789 Much Less Competent

An alternative method would be to have the subject complete the scale on a target person and also on her or himself. Difference scores between the target person and the self could then be computed as an estimate of perceived homophily on the various credibility dimensions:

A second group of similarity-dissimilarity variables that were excluded were variables which are essentially dichotomous, sex and race being prime examples. The concern of the present investigation was with the development of scales that would provide continuous measures of perceived similarities and dissimilarities. Such noncontinuous elements as sex and race, therefore, were considered peripheral to the present study.

Because of the extensive, successful use of the semantic differential technique for the measurement of other communicator perceptions, such as source credibility, a modification of this technique was chosen for this study. The extensive literature on diffusion of innovations and interpersonal attraction was reviewed in order to identify elements of similarity-dissimilarity that have been found to have an impact on interpersonal communication. As a result of this survey, a 47 -item research instrument was developed by employing adjectival phrases as bipolar scales representing all of the major elements of similarity-dissimilarity that were uncovered in the literature survey, with the exceptions noted above. The research was conducted in three phases.

\section{Procedure}

\section{PHASE 1}

The first phase of this investigation was concerned with the identification of the dimensions of perceived homophily present in our research instrument. In order to obtain this information, it w'as decided that a sample was needed having at least two characteristics. First, the Ss had to know one another and have interacted for more than a brief period of time so there would be a clear basis for perceptions of homophily. In addition, the sample needed to be reasonably heterogeneous so that there would be sufficient variance in responses for statistical analyses (particulariy factor analysis) to be meaningful. Since previous research has indicated that heterophilous individuals tend to avoid communicating with each other (Rogers \& Shoemaker. 1971 ), it was decided that the population to be used should be one that included people with considerable diversity but that, because of unusual circumstances, were put in a position where they were forced to interact with each other over a period of time and become reasonably well acquainted. The 
sample selected included 224 students enrolled in a lower-division course in small group communication at West Virginia University. The Ss included students from all of the colleges and schools in the university, represented several states, and reflected a wide variety of social and family backgrounds. Limitations of the sample that should be kept in mind when generalizing from our results include the fact that the Ss were homogeneous with respect to age (17-25), race (predominately white), culture (general American), and intellectual level (all college students).

At the time the data were collected the Ss had participated in several group discussion assignments over a period of a month. The data were collected while the Ss were seated in five-person groups that had just completed a 20 minute interaction. Each $S$ completed the research instrument for " the person on my left," " the person on my right," and "the person to whom I most often turn for advice, other than a member of my family." In each case the $S$ recorded his or her own and the other person's sex. The data collected on the two group members were considered the primary data for this study. The data concerning the person turned to for advice were believed to be related to opinion leadership.

\section{Data Analyses}

The data for the group members on the left and right were treated as different data sets. Each was submitted to principal components factor analysis and varimax rotation in an attempt to isolate independent factors. For a factor to be considered meaningful it was established that at least three items had to have satisfactory loadings (.60 or higher) on that factor with no secondary loading on another factor of above .40 . The data for the opinion leaders were scored according to the resulting factors in order to provide an estimate of the degree of perceived homophily of opinion leaders on each dimension.

\section{Results}

The factor analyses of the two data sets (left and right) yielded highly similar results. In both cases four meaningful factors were obtained. These factors were labeled Attitude, Value, Appearance, and Background. Since the two data sets provided such highly similar results, they were combined and reanalyzed together. The results, virtually identical to the two previous analyses, are summarized in Table 1.

Since opinion leaders, on the basis of previous research, are presumed to be more homophilous with their followers than are non-opinion leaders, if the present scales have any validity as an index of homophily they should reflect these differences. Consequently, the scales were summed by factor for the opinion leaders and for the people in the subject's small group (left and right). These scores, converted to a seven-step scale base (by dividing the total score by the number of items composing that score), were subjected to t-tests. The scores on three of the factors clearly reflected $(p<.01$, two-tailed) the expected distinction between opinion leaders and non-opinion leaders (Attitude: Opinion Leader $=5.11$, Non-Opinion Leader $=3.88 ;$ Value: $\mathrm{OL}=$ 5.23, $\mathrm{NOL}=3.91$; Background: $\mathrm{OL}=5.13$, NOL $=4.33)$. Scores on the Appearance factor, however, did not differ significantly $(t=<1)$. Only a small difference in the expected direction was observed $(\mathrm{OL}=3.01, \mathrm{NOL}=2.85)$. Since it was suspected that sex of subject and sex of opinion leader would be likely to confound the scores on this factor, a two-way analysis of variance was performed on the data for the subjects who had recorded both their own and their opinion leader's sex $(\mathrm{N}=186)$. A significant interaction $(\mathrm{F}=19.40$; $\mathrm{p}<.0001)$ was observed. Opinion leaders of the same sex were perceived as more homophilous on this factor than were opinion leaders of the opposite sex (Male Subjects: Male $\mathrm{OL}=3.34$, Female $\mathrm{OL}=2.47$; Female Subjects: Male $\mathrm{OL}=2.33$, Female $\mathrm{OL}=3.44$ ). Similar analyses of the data for the other factors indicated no significant interactions.

PHASE 2

Procedure

An important step in the development of a 
Table 1

Items with Satisfactory Loadings in Phases 1 and 2.

Factor

Item

Doesn't think like me-Thinks like me

Behaves like me-Doesn't behave like me

Similar to me-Different from me

Like me-Unlike me

Perceives things like me-

Doesn't perceive things like me

Personality similar to mine-

Personality different from mine

Does things unlike I do-

Does things like I do

Shares my beliefs-

Doesn $t$ share my beliefs

Shares my attitudes-

Doesn't share my attitudes

Dislikes things I dislike-

Likes things I dislike

Morals unlike mine-Morals like mine

Sexual attitudes different from mineSexual attitudes like mine

Doesn't share my values-Shares my values

Treats people like I do-

Doesn't treat people like I do

Doesn't share my emotions -

Shares my emotions

Politics different from mine-

Politics like mine

Looks different from me-

Looks similar to me

Different size than I am-Same size I am

Same weight I am-

Different weight than I am

Wears hair like I do-

Wears hair different than I do

From social class similar to mine-

From social class different from mine

Culturally different-Culturally similar

Economic situation different from mine-

Economic situation like mine

Status different from mine-

Status like mine

Family like mine-

Family different from mine

Background different from mine-

Background similar to mine

Percentage of Total Variance

*Primary loading.
Attitude Value Appearance Background

\begin{tabular}{|c|c|c|c|c|c|c|c|c|}
\hline Phase & 1 & 2 & 1 & 2 & 1 & 2 & 1 & 2 \\
\hline & $\begin{array}{r}.72 * \\
-.69 * \\
-.68 * \\
-.70 *\end{array}$ & $\begin{array}{l}-.66^{*} \\
.80^{*} \\
.82^{*} \\
.73^{*}\end{array}$ & $\begin{array}{r}.28 \\
-.17 \\
-.21 \\
-.26\end{array}$ & $\begin{array}{r}.16 \\
-.01 \\
.00 \\
-.16\end{array}$ & $\begin{array}{r}-.12 \\
.03 \\
.14 \\
-.21\end{array}$ & $\begin{array}{r}-.01 \\
.12 \\
.12 \\
.15\end{array}$ & $\begin{array}{r}.00 \\
.21 \\
.03 \\
-.10\end{array}$ & $\begin{array}{r}.15 \\
-.13 \\
-.15 \\
-.14\end{array}$ \\
\hline & $-.76^{*}$ & $.69 *$ & -.22 & -.25 & .03 & -.01 & .19 & -.19 \\
\hline & $-.63^{*}$ & $.72 *$ & -.23 & .02 & .10 & -.21 & .01 & .15 \\
\hline & $.63^{*}$ & - & .38 & - & -.19 & - & -.03 & - \\
\hline & $-.60^{*}$ & - & -.28 & - & .07 & - & .03 & - \\
\hline & $-.68 *$ & - & -.20 & - & .03 & - & .11 & - \\
\hline & $-.60 *$ & - & -.31 & - & .16 & - & -.01 & - \\
\hline & .09 & .29 & $.70 *$ & $-.72 *$ & -.14 & .13 & -.14 & -.25 \\
\hline & $\begin{array}{l}.09 \\
.24\end{array}$ & $\begin{array}{r}.15 \\
-.17\end{array}$ & $\begin{array}{l}.67 * \\
.70^{*}\end{array}$ & $\begin{array}{l}-.60 * \\
-.70 *\end{array}$ & $\begin{array}{l}-.03 \\
-.07\end{array}$ & $\begin{array}{r}.13 \\
-.13\end{array}$ & $\begin{array}{r}.05 \\
-.12\end{array}$ & $\begin{array}{r}-.29 \\
.27\end{array}$ \\
\hline & -.31 & - & $-.62 *$ & - & .11 & - & .13 & - \\
\hline & .26 & - & $.60 *$ & - & -.03 & - & .01 & - \\
\hline & .07 & - & $.60 *$ & - & -.21 & - & -.09 & - \\
\hline & .03 & .25 & -.16 & -.23 & $.67 *$ & $-.70 *$ & -.06 & .09 \\
\hline & -.17 & .24 & -.15 & -.31 & $.66 *$ & $-.73^{*}$ & -.04 & .01 \\
\hline & .21 & -.04 & .20 & -.08 & $-.61 *$ & $.79 *$ & .02 & .01 \\
\hline & .14 & -.11 & .11 & .05 & $-.71^{*}$ & $.83^{*}$ & -.11 & .05 \\
\hline & $\begin{array}{r}.07 \\
-.15\end{array}$ & $\begin{array}{r}.15 \\
-.14\end{array}$ & $\begin{array}{r}.23 \\
-.11\end{array}$ & $\begin{array}{r}-.18 \\
.03\end{array}$ & $\begin{array}{r}-.10 \\
.09\end{array}$ & $\begin{array}{l}.04 \\
.05\end{array}$ & $\begin{array}{r}.69 * 1 \\
.61^{*}\end{array}$ & $\begin{array}{r}.82^{*} \\
.81^{*}\end{array}$ \\
\hline & .23 & -.08 & .07 & .04 & -.08 & -.01 & $-.66^{*}$ & $.85^{*}$ \\
\hline & -.11 & -.19 & -.14 & -.27 & .17 & -.09 & $.61^{*}$ & $-.67^{*}$ \\
\hline & .03 & .27 & -.07 & -.14 & -.12 & .07 & $-.63^{*}$ & $-.66^{*}$ \\
\hline & .00 & - & .11 & - & .07 & - & $.62^{*}$ & - \\
\hline & 19 & 21 & 13 & 10 & 8 & 14 & 10 & 18 \\
\hline
\end{tabular}


factor-based instrument is establishing that the factors observed in one setting can be replicated under other circumstances. Consequently, 18 items representing the four factors obtained in the first phase of this investigation were combined with scales for source credibility (McCroskey, Jensen \& Valencia, 1973) and interpersonal attraction (McCroskey \& McCain, 1972) and administered to a second group of Ss enrolled in basic communication courses. In this instance, the Ss were given minimal information concerning the person about whom they were to complete the scales. They were told only that the person was in a four-member group discussion and that he or she talked a certain percentage of the time. That percentage was systematically varied from zero to 95 percent. Finally, the 519 completed instruments were submitted to factor analysis and varimax rotation employing the same criteria as in the first phase of this study.

\section{Results}

The results of the factor analysis indicated that the four dimensions presumed to be present in the data were independent of one another, and independent of measures of either source credibility or interpersonal attraction. Table 1 reports the obtained factors and item loadings, excluding the factors and items related to the other measures. No homophily item had a loading above .30 on any credibility or attraction factor. Similarly, no credibility or attraction item had a loading above .30 on any homophily dimension.

\section{PHASE 3}

The results of the first two phases suggested the presence of four dimensions of perceived homophily among college students under two conditions, when the target person was reasonably well known to the subject and when the subject had extremely little information about the target person. These results indicate that an instrument designed to measure perceived homophily generated from the results of these two phases might be expected to be quite robust, at least with other college students.
Phase 3 of this investigation was conducted to check this expectation and to examine the stability of the observed dimensions when other types of populations are involved.

\section{Procedure}

On the basis of the results of the first two phases of this investigation, a 16-item measure was generated which included four items with high loadings from each of the four observed dimensions (see Table 2). This instrument was administered to samples drawn from three populations.

College students from the same population employed in Phases 1 and 2 were asked to complete the test instrument for three target persons: "Another student in the class to whom you would prefer to go to to obtain notes and other information about the class, presuming you did not attend the day when pertinent material for the mid-term exam was reviewed," presumably an opinion leader; "Another student in the class whom you think would turn to the same person for notes and other information about the class," a follower; and "Another student in the class to whom you would not go for notes or information about the class," a non-opinion leader. A total of 576 completed instruments were obtained.

A high school sample of 191 tenth grade students at Woodrow Wilson High School in Beckley, West Virginia, was asked to complete the test instrument for four target persons: "The person in the class to whom you would prefer to go to to get notes and other information about the class, presuming you missed a class the day before a test," presumably an opinion leader; "The typical student in the same class as a source of notes and other information about the class," a non-opinion leader; "The person to whom you would prefer to go to in order to get information about an elective class you are considering taking," presumably an opinion leader; and "The typical Woodrow Wilson (high school) student as a source of information about this elective class." a non-opinion leader. Approximately half of the Ss were black and half were white. There also was an approximately equal sexual division. A 
Item Number

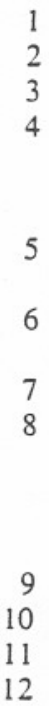

13

14

15

16

TABLE 2

A Four-Factor Measure of Perceived Homophily

Dimension

\section{Attitude}

Doesn't think like me: $\begin{array}{lllllllll}1 & 2 & 3 & 4 & 5 & 6 & 7 & \text { :Thinks like me }\end{array}$

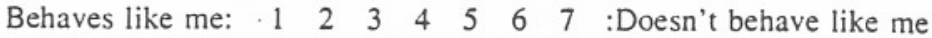

$\begin{array}{lllllllll}\text { Similar to me: } & 1 & 2 & 3 & 4 & 5 & 6 & 7 & \text { :Different from me }\end{array}$

Unlike me: $\begin{array}{lllllllll} & 1 & 2 & 3 & 4 & 5 & 6 & 7 & \text { :Like me }\end{array}$

Background

From social class

similar to mine:

Economic situation different from mine:

Status like mine: Background different from mine:

$23456, \quad$ From social class

Economic situation

$\begin{array}{llllllll}1 & 2 & 3 & 4 & 5 & 6 & 7 & \text { :like mine }\end{array}$

$\begin{array}{lllllllll}1 & 2 & 3 & 4 & 5 & 6 & 7 & \text { :Status different from mine }\end{array}$ Background similar

$\begin{array}{llllllll}2 & 3 & 4 & 5 & 6 & 7 & \text { :to mine }\end{array}$

\section{Value}

Morals unlike mine: $\begin{array}{llllllll}1 & 2 & 3 & 4 & 5 & 6 & 7 & \text { :Morals like mine }\end{array}$

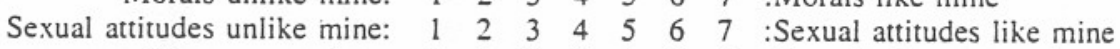

Shares my values: $\quad \begin{array}{llllllll}1 & 2 & 3 & 4 & 5 & 6 & 7 & \text { :Doesn't share my values }\end{array}$ Treats people like I do: $\quad \begin{array}{llllllll}1 & 2 & 3 & 4 & 5 & 6 & 7 & \text { :Doesn't treat people }\end{array}$ like I do

\section{Appearance}

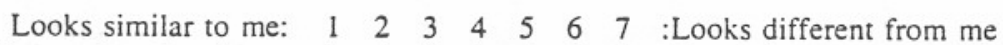
Different size than I am: $\quad \begin{array}{lllllllll}1 & 2 & 3 & 4 & 5 & 6 & 7 & \text { :Same size I am }\end{array}$ Appearance like mine: $\begin{array}{lllllllll}1 & 2 & 3 & 4 & 5 & 6 & 7 & \text { :Appearance unlike mine }\end{array}$ Doesn't resemble me: $\quad \begin{array}{lllllllll}1 & 2 & 3 & 4 & 5 & 6 & 7 & \text { :Resembles me }\end{array}$

total of 762 completed instruments were obtained.

Last, an adult sample composed of teachers and their spouses, county extension agents, and members of Kiwanis and Rotary clubs responded to the instrument. People from Ohio, Pennsylvania, and West Virginia were included in the sample. The age range was from 22 to 73 . Slightly more than half of the Ss were female, and approximately 90 percent were white; the remainder were black. Over 75 percent of the Ss were college graduates. The Ss were asked to complete the test instrument for four different opinion leaders: "The person to whom you most often turn for advice, other than a member of your family," "'The person whose opinion you most often seek concerning changing clothing styles," "The person whose opinion you most often seek concerning movies you might want to attend," and "The person whose opinion you most often seek concerning voting and candidates for political office." These targets were highly similar to ones used in previous research by Katz and Lazarsfeld (1955). A total of 1033 completed instruments were obtained.

\section{Data Analyses}

The data generated for each target person within each sample were treated as different data sets. Each data set was submitted to principal components factor analysis and varimax rotation. In each case four factors were rotated. Three and five factor solutions were also examined. The five factor solu- 
TABLE 3

Rotated Factor Loadings for College and High School Samples (College $\mathrm{N}=576$; High School $\mathrm{N}=762$ )

\begin{tabular}{|c|c|c|c|c|c|c|c|c|}
\hline \multicolumn{9}{|l|}{ Item } \\
\hline \multirow[b]{2}{*}{ Sample } & \multicolumn{2}{|c|}{ Attitude } & \multicolumn{2}{|c|}{$\begin{array}{c}\text { Value } \\
\text { (Morality) }\end{array}$} & \multicolumn{2}{|c|}{ Background } & \multicolumn{2}{|c|}{ Appearance } \\
\hline & $\mathrm{C}$ & HS & $\mathrm{C}$ & HS & C & HS & $\mathrm{C}$ & HS \\
\hline 1 & $.68^{*}$ & $.62^{*}$ & .23 & .36 & -.23 & .18 & -.11 & -.01 \\
\hline 2 & $-.83 *$ & $-.64 *$ & -.12 & -.20 & .10 & .06 & .13 & .15 \\
\hline 3 & $-.84^{*}$ & $-.67 *$ & -.08 & -.22 & .15 & -.03 & .23 & .23 \\
\hline 4 & $.76^{*}$ & $.61 *$ & .25 & .28 & -.17 & .21 & -.18 & -.18 \\
\hline 5 & -.29 & -.36 & .02 & .00 & $.79 *$ & $-.60 *$ & .00 & -.05 \\
\hline $6 * *$ & - & -.06 & - & .20 & - & $.74^{*}$ & - & -.04 \\
\hline 7 & -.26 & .21 & -.16 & -.12 & $.72 *$ & $-.60 *$ & .05 & -.01 \\
\hline 8 & .04 & .01 & .21 & .18 & $-.68^{*}$ & $.70 *$ & -.13 & -.14 \\
\hline 9 & .35 & .18 & $.80 *$ & $.72 *$ & -.17 & .15 & -.08 & .02 \\
\hline 10 & .25 & .10 & $.84^{*}$ & $.64^{*}$ & -.18 & .16 & -.11 & -.02 \\
\hline 11 & $-.57^{*}$ & $-.62 *$ & -.42 & -.05 & .23 & -.08 & .00 & -.07 \\
\hline 12 & $-.50 *$ & $-.64 *$ & -.17 & -.08 & .21 & -.13 & .05 & -.05 \\
\hline 13 & -.26 & -.06 & -.03 & .07 & .01 & -.10 & $.81^{*}$ & $.81^{*}$ \\
\hline 14 & -.07 & -.14 & -.01 & .32 & .01 & -.14 & $-.67^{*}$ & $-.65^{*}$ \\
\hline 15 & -.18 & -.28 & -.08 & .05 & .19 & -.15 & $.76^{*}$ & $.71^{*}$ \\
\hline 16 & .15 & -.07 & .12 & .18 & -.05 & -.03 & $-.82 *$ & $-.73^{*}$ \\
\hline \multicolumn{9}{|l|}{$\begin{array}{l}\text { Percent } \\
\text { of Total }\end{array}$} \\
\hline Variance & 23 & 17 & 12 & 09 & 13 & 12 & 17 & 14 \\
\hline $\begin{array}{l}\text { Primary L } \\
\text { This item }\end{array}$ & oading & 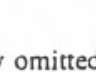 & 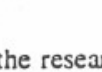 & 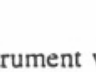 & 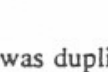 & wi & 1 & \\
\hline
\end{tabular}

tions were all rejected because each contained a fifth factor with no item having a loading of at least .60. Similarly, the three factor solutions were all rejected because, in each case, at least two items had no loading above .30 , which suggested the presence of an additional factor. Inspection of the analyses of the data sets from the same population, in each case, indicated that the factor structure did not vary on the basis of the target person; no item had its highest loading on one factor with one data set and on another with another data set. Consequently, these results will not be reported here. The data sets for each of the three samples were combined for reanalyses. The results of these analyses are reported below.

Orthogonal factor rotation of the type employed in this study assumes that existing dimensions are totally uncorrelated, and in fact forces such a result- ing factor structure. Since this assumption is tenuous at best, an additional analysis was performed on the data from the adult sample. This analysis employed oblique rotation to simple structure, a method that does not make the zero-correlation between factors assumption.

The data for the various target persons within each sample were scored according to the resulting factors in order to provide an estimate of the degree of perceived homophily of the various types of opinion leaders and other target persons on each dimension.

\section{Results}

The results of the analysis of the data from the college sample (see Table 3 ) indicated the presence of four factors accounting for 65 percent of the total 
TABLE 4

Orthogonal and Oblique Rotations of Factor Analysis of Adult Sample Data $(\mathrm{N}=1033)$

\begin{tabular}{|c|c|c|c|c|c|c|c|c|}
\hline \multirow[b]{3}{*}{ Item } & \multicolumn{8}{|c|}{ Factor } \\
\hline & \multicolumn{2}{|c|}{ Attitude } & \multicolumn{2}{|c|}{ Value (Morality) } & \multicolumn{2}{|c|}{ Background } & \multicolumn{2}{|c|}{ Appearance } \\
\hline & Orth & Obliq & Orth & Obliq & Orth & Obliq & Orth & Obliq \\
\hline 1 & $.50 *$ & $.46^{*}$ & .44 & -.39 & -.11 & -.02 & .13 & -.08 \\
\hline 2 & $-.67^{*}$ & $-.67 *$ & -.20 & .14 & .02 & -.08 & -.12 & .06 \\
\hline 3 & $-.73^{*}$ & $-.73^{*}$ & -.15 & .06 & .08 & -.03 & -.26 & .21 \\
\hline 4 & $.64^{*}$ & $.60 *$ & .31 & -.23 & -.14 & -.04 & .28 & -.23 \\
\hline 5 & -.36 & -.27 & .03 & -.14 & $.71^{* *}$ & $.69 *$ & -.02 & -.01 \\
\hline 6 & -.01 & -.14 & .23 & -.17 & $-.67 *$ & $-.70 *$ & .03 & -.02 \\
\hline 7 & -.34 & -.28 & .08 & -.17 & $.60 *$ & $.58^{*}$ & .03 &. .06 \\
\hline 8 & .00 & -.15 & .24 & -.17 & $-.67 *$ & $-.69 *$ & .13 & -.11 \\
\hline 9 & .21 & .11 & $.78^{*}$ & $-.76^{*}$ & -.19 & -.14 & -.02 & .07 \\
\hline 10 & .18 & .10 & $.81^{*}$ & $-.81 *$ & -.09 & -.04 & -.02 & .06 \\
\hline 11 & $-.61^{*}$ & $-.60 *$ & -.17 & .09 & .26 & .18 & .14 & -.19 \\
\hline 12 & $-.70 *$ & $-.72 *$ & .05 & -.13 & .13 & .03 & .00 & -.05 \\
\hline 13 & -.12 & -.05 & .08 & -.13 & .12 & .11 & $-.80^{*}$ & $.81^{*}$ \\
\hline 14 & -.06 & -.10 & .10 & -.10 & .12 & .12 & $.62 *$ & $-.63^{*}$ \\
\hline 15 & -.20 & -.14 & -.03 & -.02 & .05 & .02 & $-.73^{*}$ & $.72 *$ \\
\hline 16 & .10 & .03 & -.04 & .09 & -.10 & -.10 & $.81^{*}$ & $-.81^{*}$ \\
\hline \multicolumn{9}{|l|}{$\begin{array}{l}\text { Percent } \\
\text { of Total }\end{array}$} \\
\hline $\begin{array}{l}\text { of Total } \\
\text { Variance }\end{array}$ & 17 & 17 & 11 & 11 & 12 & 12 & 15 & 15 \\
\hline *Primary Loa & & & & & & & & \\
\hline
\end{tabular}

variance. All of the items expected to load on the Attitude, Background, and Appearance factors did so. Two of the items expected to load on the Value factor did so, but the other two loaded on the Attitude factor. The two items loading on the Value dimension concerned similarity of morals and sexual attitudes. This suggests that the factor should probably be labeled "Morality" rather than "Value."

The results of the analysis of the data from the high school sample (see Table 3 ) indicated a structure highly similar to that obtained from the college sample, except that less total variance ( 52 percent) was accounted for. The same two items from the Value dimension loaded with the Attitude factor, again suggesting the need to change the label of the former factor.

Both the orthogonal and the oblique rotation analyses of the data from the adult sample (see
Table 4) yielded results highly similar to those from the college and high school samples. Both analyses accounted for 55 percent of the total variance. The oblique structure resulted in factors which were essentially uncorrelated. Only two of the six correlations were above .20. The Attitude and ValueMorality factors had a correlation of .23; the Attitude and Background factors had a correlation of .31. The same two Value items loaded with the Attitude factor with both rotational procedures. The only noticeable difference between the results from this sample and those from the other samples was that one item on the Attitude dimension (doesn't think like me-thinks like me) had a somewhat lower loading on that factor (.50) in this sample.

The data scored by factor and converted to a seven-step scale base for each target person for each sample are reported in Table 5. The college and high school subjects completed the test instrument 
TABLE 5

Mean Scores on Factors for Target Persons in Phase 3 Samples*

Factor

Sample-Target
College
Opinion Leader
Follower
Non-Opinion Leader
High School
Opinion Leader-Notes
Typical Student-Notes
Opinion Leader-Class
Typical Student-Class
Adult
Opinion Leader-General
Opinion Leader-Movies
Opinion Leader-Fashion
Opinion Leader-Politics
3.00

Attitude

$4.52 \mathrm{a}$

$4.07 \mathrm{a}$

$2.42 \mathrm{a}$

$4.43 a$

$3.81 \mathrm{a}$

$4.19 \mathrm{~b}$

$3.93 \mathrm{~b}$

4.53

4.59

4.65

4.48
Value (Morality)
4.60a
$4.17 \mathrm{a}$
3.12a

$4.62 \mathrm{a}$

$4.08 \mathrm{a}$

$4.20 \mathrm{~b}$

$3.98 \mathrm{~b}$

5.03

5.14

5.10

4.89
Background

$4.50 \mathrm{a}$
$4.17 \mathrm{a}$
$3.47 \mathrm{a}$

4.46

4.21

4.14

4.24

4.72

4.86

4.97

5.03
Appearance

$3.17 \mathrm{a}$

$3.14 \mathrm{~b}$

$2.76 a, b$

3.07

3.26

3.22

3.36

*Higher scores reflect greater perceived homophily.

a.b means with name subscript on the same factor, within the same sample, are significantly different, $p<.05$.

for both opinion leaders and other target persons. Since opinion leaders are theoretically more homophilous with their followers than most other people (Rogers \& Shoemaker, 1971), an indication of validity of the test instrument would be the obtaining of significant differences in homophily scores on the various dimensions between opinion leaders and non-opinion leaders. Consequently the observed differences were tested for significance by means of repeated measures analysis of variance followed by post hoc comparisons employing the Scheffe procedure. Significant differences $(\mathrm{p}<.05$, two-tailed test) are indicated in Table 5.

As is indicated in Table 5, the expected significant differences were obtained for all comparisons made on the Attitude and Morality factors. Expected significant differences on the Background factor were obtained with the college sample, but not with the high school sample. Possibly the high homogeneity of background of the high school subjects militated against significance on this factor with this sample. Although significant differences were observed on the Appearance factor with the college sample, none were observed with the high school sample, and the absolute scores for the opinion leaders in all three samples suggest that this factor considered alone may not be a meaningful discriminator between opinion leaders and other target persons. As noted previously, this factor is highly influenced by the sex of the subject and the sex of the target person. Thus the sex of both individuals must be taken into account before data on this factor can be interpreted meaningfully.

The results reported in Table 5, as well as those in the initial study, provide substantial support for the concept of optimal heterophily. Although opinion leaders were perceived as more homophilous than other target persons, the absolute scores on the dimensions were substantially below the point of maximum homophily (7.0). At this point it appears that too much homophily, as well as too little homophily, may lead to the rejection of an individual as an opinion leader.

\section{CONCLUSIONS}

The results of this investigation suggest that there are at least four relatively uncorrelated dimensions 
of perceived homophily: Attitude, Morality, Background, and Appearance. The first three dimensions distinguished between opinion leaders and other target persons, with the former being perceived as more homophilous. The results indicate, however, that meaningful interpretation of the data from the Appearance dimension requires consideration of the sex of both the respondent and the target person.

The scales for these dimensions of homophily listed in Table 2 (omitting Items 11 and 12) were found to be satisfactory for samples from three highly diverse populations. Consequently, these 14 scales should provide a useful measure of homophily for researchers concerned with this important communication variable.

One reservation must be stressed at this point. The results of this investigation may be interpreted as indicating that there are at least four dimensions of perceived homophily. However, it would be erroneous to conclude that these four dimensions exhaust the substance of the homophily construct. The methodology employed in this investigation, factor analysis, is appropriate for determining the dimensions of perception present in a test instrument. Of course, if no items representing a dimension are present, that dimension cannot appear in the resulting factor structure. An observed factor structure can do no better than the sample of items on which it is based. It is highly likely that later research will be able to isolate additional homophily dimensions, particularly if that research takes into account special circumstances related to particular communication environments, such as the supervisorsubordinate relationship in an organizational environment.

\section{REFERENCES}

ALPERT, M.I., \& ANDERSON, W.T., JR. Optimal heterophily and communication effectiveness. Some empirical findings. Journal of Communication, 1973, 23, 328-343.

BERSCHEID, E., \& WALSTER. E.H. Interpersonal attraction. Reading, Mass.: Addison-Wesley, 1969.

BYRNE. D. Interpersonal attraction and attitude similar- ity. Journal of Abnormal and Social Psychology, 1961, 62, 713-715.

KATZ, E., \& LAZARSFELD, P.F. Interpersonal influence. New York: Free Press, 1955.

KING, S.W., \& SERENO, K.K. Attitude change as a function of degree and type of interpersonal similarity and message type. Western Speech, 1973, 37, 218-232.

LITTLEJOHN, S.W. A bibliography of studies related to variables of source credibility. In N.A. Shearer (Ed.), Bibliographic annual in speech communication, $\mathrm{Vol}$. 2. New York: SCA, 1971, 1-40.

MCCROSKEY, J.C., \& MCCAIN, T.A. The Measurement of interpersonal attraction. Speech Monographs, 1974, 4, 261-266.

MCCROSKEY, J.C., JENSEN, T., \& VALENCIA, C. Measurement of the credibility of peers and spouses. Paper presented at the International Communication Association Convention, Montreal, 1973.

ROGERS, E.M., \& BHOWMIK, D.K. Homophilyheterophily: Relational concepts for communication research. Public Opinion Quarterly, 1970, 34. 523-538.

ROGERS. E.M., \& SHOE.MAKER, F.F. Commu- nica tion of innovations. New York: Free Press, 1971.

SIMONS, H.W., BERKOWITZ, N.M., \& MOYER, R.J. Similarity, credibility, and attitude change: a review and a theory. Psychological Bulletin, 1970, $73,1-16$.

WHEELESS, L.R. The effects of attitude, credibility, and homophily on selective exposure to information. Paper presented at the International Communication Association Convention, Montreal, 1973. 